\title{
Late effects of total body irradiation
}

Total body irradiation (TBI) is a powerful but potentially hazardous tool used in the eradication of malignant cells and the suppression of the immune system to enable bone marrow engraftment. The occasion of its use is confined to bone marrow transplantation (BMT) in malignant disorders and some non-malignant haematological and metabolic conditions and is accompanied by high dose chemotherapy. Since infection and graft versus host disease (GVHD) may also complicate BMT untangling factors leading to late sequelae may be a difficult task and frequently there is more than one cause of any single pathological event.

The radiation dose employed in TBI is as high above the median lethal dose $\left(\mathrm{LD}_{50}\right)$ for 'marrow death' as possible before encountering significant bowel or lung toxicity. Most early experience was gained with single fraction TBI and doses of up to a $10 \mathrm{~Gy}$ proved effective and safe; if fast dose rates were used the acute toxicity increased unless the total dose was lowered. Latterly and as in virtually all other clinical radiotherapy the benefits of fractionation have been realised. By dividing the TBI dose in several fractions over a number of days the acute toxicity is lowered, the total TBI dose may be safely raised (for example 12-15 Gy in six fractions), and dose rate is less important. ${ }^{1}$ Of great significance is the fact that the higher total dose achieved by fractionation probably allows greater leukaemic cell kill and the lower doses per fraction reduce the late normal tissue morbidity. This forms the basis for this review which will focus on late sequelae of TBI usually presenting a year or more from exposure. They can be grouped into late effects pertaining to growth and the endocrine system, specific organs, and second malignancy.

\section{Growth and the endocrine dysfunction}

Growth failure after TBI may be attributed to a number of factors and varies according to the type of fractionation schedule. Endocrine dysfunction ${ }^{2-4}$ and epiphysial growth plate damage (skeletal dysplasia) ${ }^{5}$ are the main direct effects of TBI. There is a significant decrease in height SD scores after both 9-10 Gy of TBI in a single fraction and 12-14 Gy TBI given in 6-8 fractions. Height is significantly more impaired three years after TBI in the single fraction group (height SD score -0.9 compared with -0.22 respectively) despite the lower total dose of radiation. ${ }^{6}$ There is evidence of segmental disproportion in both groups with diminished sitting height compared with subischial leg length. However, this may be accounted for by chemotherapy antedating TBI as there is now evidence that this may have a disproportionate effect on spinal growth compared with other epiphyses. ${ }^{7}$

Growth hormone deficiency occurs in patients receiving TBI even without previous cranial irradiation, although the mean peak growth hormone concentrations are usually lower in those who have been previously irradiated (in acute lymphoblastic leukaemia). Growth hormone treatment after TBI only maintains a normal growth rate and does not give rise to catch up growth or affect the disproportionate spinal growth. ${ }^{8}$

Primary thyroid dysfunction is commonplace after TBI but fractionated schedules give rise to a much lower incidence of both overt hypothyroidism and thyroid stimulating hormone abnormalities (59-73\% compared with $16-25 \%{ }^{910}$. The risk of hypothyroidism, however, continues over a life time and eventually careful follow up may reveal an equally high incidence. Occasionally there is spontaneous recovery. ${ }^{4}$ It is customary to treat raised concentrations of thyroid stimulating hormone with replacement thyroxine therapy even if the patient is euthyroid but there is no evidence that high thyroid stimulating hormone stimulates neoplastic change in humans. ${ }^{11}$

Growth at puberty is dependent on the interaction of growth hormone with sex steroids and strict attention should be paid both to growth hormone status and sexual maturation at adolescence. TBI and alkylating agents such as busulphan and cyclophosphamide all have an effect on the gonad and in the transplant situation one cannot be considered with the other. It is recognised that almost all girls and boys transplanted before puberty and in the young adult period will recover normal sexual function after cyclophosphamide alone. ${ }^{12-14}$ After TBI, however, the situation is different. In one large series, 30 of 42 girls and 51 of 65 boys currently greater than 12 years of age but transplanted in the prepubertal period had delayed sexual development accompanied by raised gonadotrophins and subnormal sex steroid concentrations indicating gonadal failure. The 14 boys developing secondary sexual characteristics at the appropriate age all had fractionated TBI, whereas of the 12 girls with age appropriate development six had received single fraction and six fractionated TBI. ${ }^{14}$

It is recommended that children with delayed pubertal development should be given sex steroid supplementation early not only to avoid psychological problems but also to ensure an adequate growth velocity during this important growing period.

Return of ovarian function and fertility (10 out of 380) has been reported in the postmenarcheal female transplanted at less than 26 years of age particularly after fractionated TBI. The low incidence of pregnancies and the high risk nature of these pregnancies, however, means that all patients should be warned of the likelihood of infertility (J E Sanders, data presented at workshop on female fertility after BMT, Royal Marsden Hospital, 199313 14). The potential for a normal pregnancy is further compromised by reduced uterine blood flow and failure of the uterus to increase in size at puberty despite adequate oestrogenisation. ${ }^{15}$ Of 323 adult males only five demonstrated return of spermatogenesis after TBI. ${ }^{13} 14$

\section{Organ specific damage}

With increasing survival of patients treated with TBI/BMT new late sequelae are constantly being observed. After growth failure and endocrine dysfunction damage to the lungs, cardiovascular system, kidney, eye, and brain are the commonest sequelae found but the use of anthracyclines, aminoglycoside antibiotics, and amphotericin and the occurrence of GVHD are often contributory. ${ }^{15}$

\section{CARDIOVASCULAR SEQUELAE}

Survivors of childhood malignancy represent one of the largest risk groups for premature cardiovascular disease. ${ }^{16}$ Late and perhaps progressive cardiotoxicity is a serious side effect of mediastinal radiation. Much information has been gained from studying patients treated for Hodgkin's disease in childhood. ${ }^{17}$ They have had a higher dose of mediastinal radiation than would be delivered during TBI but in a greater number of fractions, which suggests that TBI may be just as damaging. 
The cardiovascular system may be directly or indirectly affected by radiation treatment. The direct affects are on the pericardium, myocardium, endocardium valves, conduction system, and coronary arteries and may become clinically significant over time presenting as cardiomyopathy, sudden death, or arrhythmias. ${ }^{16}$ Radiation also damages endothelial cells resulting in a loss of capillaries and ischaemia at the microcirculatory level and fibrosis results. This tends to present late and often in adulthood as progressive pericardial thickening, cardiac valve thickening and deformity, and fibrotic vascular damage all of which tend to pursue a serious course with poor prognosis. ${ }^{16}$ Sinus node and atrioventricular conduction block and arterial occlusive disease and strokes are also recognised complications of irradiation treatment. ${ }^{16}$

The role of anthracyclines in the pathogenesis of dose related cardiotoxicity (particularly cardiomyopathy) and the synergistic effect between mediastinal irradiation and these chemotherapeutic agents is well known. ${ }^{18} 19$ In addition other drugs, for example cyclophosphamide, used in conditioning prior to TBI may also add to the cardiotoxicity.

A present there is no effective preventative treatment for the development of radiation related cardiovascular disease and accurate monitoring of cardiac structure, function, and pericardial disease by echocardiography and the detection of coronary artery disease and conduction defects by exercise stress testing and 24 hour electrocardiographic recording should be vigorously pursued. Although few of our TBI patients have presented with symptomatic cardiac dysfunction so far clinicians should have a low threshold for suspicious symptoms even in the face of extreme youth of the patient. I suspect that many cardiovascular complications may not yet have presented in our young population but may be lying in store until mid adult life.

\section{PULMONARY SEQUELAE}

Pulmonary late effects appear to be less common in the paediatric population than in adults. TBI is only one of many contributory factors to lung disease and cannot be solely implicated in any situation. Pulmonary interstitial tissue is particularly sensitive to cytotoxic agents as well as to radiation, and the lungs and airways are also targets for microbial and fungal infection and GVHD causing additional severe structural and functional damage. As a result delayed and chronic pulmonary complications may occur.

Restrictive defects of ventilatory function are common in marrow recipients, even those who are healthy long term survivors. Springmeyer et al found that $20 \%$ of their population showed a reduction in total lung capacity, vital capacity, and impairment of diffusing capacity one year after $B M T .{ }^{20}$ Lung function tends to improve over the subsequent 3-4 years and may stabilise or completely normalise. This is confirmed by Tait $e t$ al who also found the occurrence of permanent subclinical obstructive defects but these were worse and continued to increase beyond two years in patients with GVHD. ${ }^{21}$ Severe obstructive airways disease is uncommon except in those in whom GVHD is manifested by obliterative bronchiolitis. Patients who experience idiopathic interstitial pneumonitis early after BMT have greater defects. ${ }^{20} 22$

Idiopathic interstitial pneumonia where diffuse pulmonary infiltrates (alveolar or interstitial) and no microbial agents are detected is usually an early event after BMT within 100 days but uncommonly presents late. It may be insidious presenting with changes on routine chest radiography or lung function tests but the usual clinical picture is one of hypoxaemia, tachypnoea, non-productive cough, with or without fever. The prognosis is poor and there is no known effective treatment. The host of risk factors include increased dose of TBI and dose delivery rate and single fractionation. ${ }^{23}$

\section{RENAL SEQUELAE}

Although early renal toxicity, often due to nephrotoxic agents and related to the transplant period, has been recognised for some long time, late nephrotoxicity is a relatively newly reported phenomenon in children. Radiation nephropathy occurring at higher doses than those given in TBI is well documented. Generally, $20 \mathrm{~Gy}$ of once daily fractionated radiation to both kidneys has been considered the tolerance level before the onset of significant radiation injury. ${ }^{24-26}$ Lately there have been several publications indicating a syndrome of late onset renal dysfunction consistent with radiation nephritis. ${ }^{27-29}$ It tends to occur within one year of BMT in children conditioned with intensive multiagent chemotherapy and TBI. Presentation is often as the haemolytic uraemic syndrome or as progressive renal failure. Most patients show anaemia, increased concentrations of creatinine and blood urea and microscopic haematuria with evidence of microvascular haemolysis. Renal biopsy specimens consistently show intraglomerular mesangiolysis, mesangioproliferation, and arteriolonecrosis. Recovery or stabilisation of function occur in some while in others there is progressive renal failure. ${ }^{27-29}$

In our practice, late renal sequelae are unusual and it is generally assumed that radiation nephropathy has been precipitated by unusually intensive conditioning in the reported patients, lowering the threshold of the kidney to radiation injury. ${ }^{28}$

We have seen late onset hypertension requiring therapeutic intervention in adolescents up to eight years after BMT but with otherwise normal renal function.

\section{NEUROPSYCHOLOGICAL}

Marrow transplantation is now a common treatment for leukaemic relapse and TBI conditioning may lead to undesirable neurological sequelae. Many children with relapsed acute lymphoblastic leukaemia already will have received cranial irradiation with regular intrathecal methotrexate as part of central nervous system directed therapy for their initial disease. Such a combination is known to be associated with a spectrum of neurological deficits from subtle learning difficulties, ${ }^{30} 31$ attentional deficits, ${ }^{32}$ and low or declining IQ scores and memory impairment ${ }^{32-34}$ through to severe necrotising leucoencephalopathy with progressive neurological deterioration. ${ }^{35}$ Changes on computed tomography frequently appear as attenuation of the white matter, ventricular dilatation, and intracerebral calcifications, which are thought to reflect demyelination, cerebral atrophy, and mineralising microangiopathy. ${ }^{36}$ Young age of the patient is shown to be associated with poorer educational attainment ${ }^{37}$ and a greater incidence of changes on computed tomography, fits, and low IQ on completion of treatment. ${ }^{38}$ Female sex also mitigates against good educational performance. ${ }^{39}$ Little has been written about the effects of TBI on neurological function but a recent report from our centre indicated that of 14 patients receiving a second course of brain irradiation either as TBI or as cranial irradiation, all suffered from a variety of neurological deficits presenting with at least one soft neurological sign, such as diminished fine motor control and poor coordination. ${ }^{40}$ The vast majority of patients showed selective reduction in verbal IQ attention and concentration and girls showed 
greater impairment than boys. ${ }^{40}$ Although no difference in cognitive outcome has been found between doses of 18 and $24 \mathrm{~Gy}$ of cranial irradiation a shorter interval between two radiation exposures and higher cumulative doses of radiotherapy all correlated with poorer cognitive function in our recent publication. ${ }^{40}$

In addition to neurological and cognitive deficits, psychological distress born of prolonged hospitalisation, intensive treatment, and the threat of disease recurrence should be addressed with equal effort and sympathy as with physical sequelae.

\section{OPHTHALMIC COMPLICATIONS}

Radiation has long been known to be a cause of cataracts of the posterior subcapsular type in a dose related fashion. ${ }^{41}$ The cataractogenic nature of steroids is also proved, ${ }^{42} 43$ and more recently it has been suggested that antineoplastic drugs may induce cataracts. ${ }^{44}$ In one large study from Seattle a comparison was made in the incidence of cataracts among patients conditioned for BMT with single fraction TBI, and fractionated TBI. The risk of developing cataracts was estimated to be $80 \%$ for single fraction and $18 \%$ for fractionated TBI, suggesting a significant sparing effect of fractionated irradiation. ${ }^{45} \mathrm{~A}$ more recent study looking at development of cataracts in children echoes our own experience showing that almost all $(94 \%)$ patients with leukaemia receiving single fraction TBI develop cataracts by three years from exposure. The progression of the cataract was most pronounced during the first four year period and the mean time to onset of cataract formation was $2 \cdot 2$ years (range 1-3 years). No relationship was found between age and onset of treatment, sex of the patient, or steroid treatment given for GVHD unlike in the Seattle study. ${ }^{46}$ Surgery is well tolerated and successful but seems to be more often necessary when single dose TBI is given. ${ }^{45}$ Various other syndromes after BMT have been described such as keratoconjunctivitis sicca and obstruction of the nasolacrimal duct which may be a manifestation of GVHD or be due to TBI.

\section{TEETH}

Radiation to the head and neck can cause impairment of growth of deciduous or permanent teeth and diminished secretion of saliva. ${ }^{47}$ It may also impair dentine and enamel formation and lead to hypoplasia of the mandible and/or maxilla. In addition, it may give rise to tooth and root shortening and, in some cases, complete lack of tooth development depending on the age of the patient at the time of irradiation. Tooth decay is common and often presents uniquely on surfaces which are usually immune to decay as well as at characteristic sites. ${ }^{47}$ Chemotherapy administration alone can produce significant alteration in dental development and cause decay and a combination of both treatment modalities may severely affect dentition. ${ }^{47}$ Regular dental examination and attention to oral hygiene and diet is mandatory.

BONE

Growth impairment by radiation has already been mentioned in sections relating to growth and the endocrine system and the teeth. The appearance of benign exostoses are alluded to in the section on second neoplasms. The diagnosis of avascular necrosis of bone is traditionally linked to the use of steroids, but it is a relatively common condition among the transplant population and may present insidiously, often after a variable degree of delay. The contribution from TBI to this condition is unknown.

\section{Second malignancy}

Individuals with a history of childhood cancer have been estimated to have 10-20 times the life time risk of a second malignancy compared with age matched controls. ${ }^{48}$ The incidence within 20 years of diagnosis appears to vary from $3-12 \%$ reflecting variability in intensity and the type of regimen of chemoradiotherapy. ${ }^{4950}$ The aetiology of secondary cancer is multifactorial with evidence pointing at reduction of immune surveillance due to immunosuppression, genetic predisposition, and the oncogenic potential of chemotherapy, particularly alkylating agents and epipodophyllotoxins. ${ }^{51-53}$ Radiotherapy also plays a large part and second tumours that may occur in a dose related fashion are often found within the radiation field. ${ }^{52}$ Brain tumours have been reported in association with radiotherapy in childhood acute lymphoblastic leukaemia and tineacapitis ${ }^{54}$ and thyroid neoplasms after radiotherapy for Hodgkin's disease. ${ }^{55}$

Dogs given dog leucocyte antigen identical marrow after TBI have an incidence of second tumours five times higher than that of unirradiated controls, ${ }^{56}$ and it is reasonable to suppose that secondary cancer may be commoner after BMT conditioned with TBI than with chemotherapy alone.

In a large series from Seattle of 2246 bone marrow recipients with leukaemia and aplastic anaemia Witherspoon et al reported an incidence of secondary malignancy 6.69 times higher than primary cancer in the general population. ${ }^{57}$ In multivariate analysis TBI, among other factors, was a predictor for secondary malignancy. Those patients conditioned with TBI had a relative risk of 3.9 compared with those who remained unirradiated.

Recently, a French study found a cumulative incidence of second solid tumours at eight years of $22 \%$ in patients with aplastic and Fanconi's anaemia conditioned with cyclophosphamide and thorocoabdominal irradiation. ${ }^{58}$ This contrasted strongly with an incidence of $1.4 \%$ at 10 years in the Seattle experience using cyclophosphamide alone before marrow transplantation in similar patients. ${ }^{59}$ The implication that radiation has played a part in the development of these tumours is strong and where possible TBI should be excluded from conditioning regimens before BMT for non-malignant disorders. The type of second malignancies found are non-Hodgkin's lymphomas often of B lymphocyte origin, known to be Epstein-Barr virus and immune suppression associated, leukaemias, gliomas, melanoma, squamous cell carcinomas, bone and soft tissue sarcomas, and thyroid neoplasms, ${ }^{12} 57$ all of which can be associated with radiotherapy.

Multiple benign exostoses and widespread pigmented naevi are commonly found in association with TBI and chemotherapy. ${ }^{60}$ The tendency of these towards malignancy is as yet unknown but the risks of melanoma are higher in patients with multiple naevi and great care should be taken to protect the skin from the sun's carcinogenic potential. Between 5 and $25 \%$ of multiple exostoses undergo malignant change to chondrosarcoma and more rarely to osteosarcoma ${ }^{61}$ but so far these have not been reported after TBI.

\section{Conclusion}

Survival after BMT for malignant disease is an expanding field and the beneficial effects of TBI are clear for all to see. The deleterious effects, however, are often delayed and may be of insidious onset and there is no room for complacency when monitoring these patients. New late sequelae are constantly attracting the limelight when transplantation has been carried out in childhood and there is strong suspicion among oncologists that we have not yet 
seen the last. Vigilance and attention to detail is paramount.

Department of Haematology and Oncology,

ALISON D LEIPER

Great Ormond Street Hospital for Children NHS Trust,

London WC1N $39 H$

1 Plowman PN. A review of total body irradiation. Br $\mathcal{f}$ Radiol 1987; 22 (suppl): 135-45.

2 Sanders JE, Pritchard S, Mahoney P, et al. Growth and development following bone marrow transplantation for leukaemia. Blood 1986; 68: $1129-35$.

3 Sanders JE. Endocrine problems in children after BMT for haematological malignancies. Bone Marrow Transplant 1991; 8 (suppl 1): 2-4.

4 Leiper AD, Stanhope R, Lau T, et al. The effect of total body irradiation and bone marrow transplantation during childhood and adolescence on growth and endocrine function. $\mathrm{Br} \mathcal{F}$ Haematol 1987; 67: 419-26.

5 Donaldson S. Effects of irradiation on skeletal growth and development. In Green D, D'Angio G, eds. Late effects of treatment for childhood cancer. New York: Wiley-Liss, 1992: 63-70.

6 Thomas BC, Plowman PN, Leiper AD, et al. Growth following single fraction and fractionated total body irradiation for bone marrow transplantation. Eur F Pediatr 1993; 152: 888-92.

7 Davies HA, Didcock E, Didi M, Ogilvy-Stuart A, Wales JKH, Shalet SM. Disproportionate short stature after cranial irradiation and combination chemotherapy for leukaemia. Arch Dis Child 1994; 70: 472-5.

8 Papadimitriou A, Urena M, Hamill G, Stanhope R, Leiper AD. Growth hormone treatment of growth failure secondary to total body irradiation hormone treatment of growth failure secondary to total body irradiat

9 Thomas BC, Stanhope R, Leiper AD, et al. Endocrine function following single fraction and fractionated total body irradiation for bone marrow transplantation in childhood. Acta Endocrinol (Copenh) 1993; 128 508-12.

10 Ogilvy-Stuart AL, Clarke DJ, Wallace WHB, et al. Endocrine deficit after fractionated total body irradiation. Arch Dis Child 1992; 67: 1107-10.

11 Katsanis E, Shapira RS, Robison LL, et al. Thyroid dysfunction following bone marrow transplantation: long-term follow up of 80 paediatric patients. Bone Marrow Transplant 1990; 5: 335-40.

12 Sanders JE, Buckner CD, Sullivan KM, et al. Growth and development in children after bone marrow transplantation. Horm Res 1988; 30: 92-7.

13 Sanders JE. The impact of marrow transplant preparative regimens on subsequent growth and development. Semin Hematol 1991; 28: 244-9.

14 Sanders JE. Growth and development after BMT. In: Forman SJ, Blume KG, Thomas ED, eds. Bone marrow transplantation. Boston: Blume KG, Thomas ED, eds. B
Blackwell Scientific, 1994: 527-37.

15 Liesner R, Leiper AD, Hann IM, et al. Late effects of intensive treatment for acute myeloid leukaemia and myelodysplasia in children. $\mathscr{f}$ Clin Oncol 1994; 12: 916-24.

16 Lipshulz SE, Sallan SE. Cardiovascular abnormalities in long-term survivors of childhood malignancy [Editorial]. I Clin Oncol 1993; 11: 1199-203.

17 Hancock SL, Donaldson S, Hoppe R. Cardiac disease following treatment of Hodgkin's disease in children and adolescents. I Clin Oncol 1993; 11: 1208-15

18 Lipshultz SE, Colan SD, Gelber RD, et al. Late cardiac effects of doxorubicin therapy for ALL in childhood. $N$ Engl f Med 1991; 324: 808-15.

19 Arsenian MA. Cardiovascular sequelae of therapeutic thoracic radiation. Prog Cardiovasc Dis 1991; 33: 299-312.

20 Springmeyer SC, Flournoy N, Sullivan KM, et al. Pulmonary function changes in long term survivors of allogeneic marrow transplantation. In: Gale RP, ed. Recent advances in bone marrow transplantation. New York: Alan R Liss, 1983: 343-53.

21 Tait DC, Burnett AK, Robertson AG, et al. Subclinical pulmonary function defects following autologous and allogeneic bone marrow transplantation. defects following autologous and allogeneic bone

22 Deeg HJ. Delayed complications after BMT. In: Forman SJ, Blume KG, Thomas ED, eds. Bone marrow transplantation. Boston: Blackwell Scientific, 1994: 538-44.

23 Keane TJ, van Dyk J, Rider WD. Idiopathic interstitial pneumonia following marrow transplantation: the relationship with TBI. Int $\mathcal{F}$ Radiat Oncol Biol Phys 1981; 7: 1365-70.

24 Keene WF, Crosson JT, Staley NA, et al. Radiation-induced renal disease. Am $\mathcal{}$ Med 1976; 60: 127-37.

25 Kunkler PP, Farr RF, Luxton RW. The limit of renal tolerance to X-rays. $B r$ I Radiol 1952; 25: 190.

26 Luxton RW. Radiation nephritis. Lancet 1960; ii: 1221.

27 Tarbell NJ, Guinan EC, Niemeyer C, et al. Late onset of renal dysfunction in survivors of bone marrow transplantation. Int $\mathcal{F}$ Radiat Oncol Biol Phys 1988; 15: 99-104.

28 Guinan EC, Tarbell NJ, Niemeyer C, et al. Intravascular haemolysis and renal insufficiency after bone marrow transplantation. Blood 1988; 72: 451-5.

29 Antignac C, Gubler H, Leverger G. Delayed renal failure with extensive mesangiolysis following bone marrow transplantation. Kidney Int 1989; 35: $1336-44$.
30 Jannoun L, Chessells JM. Long-term psychological effects of childhood leukaemia and its treatment. Pediatr Hematol Oncol 1987; 4: 293-308.

31 Eiser C. Intellectual abilities among survivors of childhood leukaemia as a function of CNS irradiation. Arch Dis Child 1978; 53: 391-5.

32 Browers P, Riccardi R, Poplack DG, et al. Attentional deficits in long-term survivors of childhood acute lymphoblastic leukaemia (ALL). Fournal of Clinical Neuropsychology 1984; 6: 325-36.

33 Copeland DR, Dowell RE, Fletcher JM, et al. Neuropsychological test performance of paediatric cancer patients at diagnosis and one year after. f Pediatr Psychol 1988; 13: 183-96.

34 Meadows TA, Massari DJ, Fergusson J, et al. Declines in IQ scores and cognitive function in children with acute lymphoblastic leukaemia treated nitive function in children with acute lymphob
with cranial irradiation. Lancet 1981; ii: 1015-8.

35 Bleyer A. Neurological sequelae of methotrexate and ionising radiation: a new classification. Cancer Treat Rev 1981; 65: 89-98.

36 Peylan-Ramu N, Poplack DG, Pizzo PA, et al. Abnormal CT scans of the brain in asymptomatic children with acute lymphatic leukaemia after brain in asymptomatic children with acute lymphatic leukaemia after prophylactic treatment of the central nervous system with
intrathecal chemotherapy. $N$ Engl F Med 1978; 298: 815-9.

37 Jannoun L. Are cognitive and educational developments affected by age at which prophylactic therapy is given in acute lymphoblastic leukaemia. Arch Dis Child 1983; 58: 953-8.

38 Chessells JM, Cox TCS, Kendall B, Cavanagh NPC, Jannoun L, Richards S. Neurotoxicity in lymphoblastic leukaemia: comparison of oral and intramuscular methotrexate and two doses of radiation. Arch Dis Child 1990; 65: 416-22.

39 Waber DP, Tarbell NJ, Kahn CM, et al. The relationship of sex and treatment modality to neuropsychologic outcome in childhood acute lymphoblastic leukaemia. 7 Clin Oncol 1992; 10: 810-7.

40 Christie D, Battin M, Leiper AD. Neuropsychological and neurological outcome after relapse of lymphoblastic leukaemia. Arch Dis Child 1994;

41 Merriam CR, Focht EF. Clinical study of radiation cataracts and the reaction to dose. AfR 1957; 77: 759-85.

42 Axelrod L. Glucocorticoid therapy. Medicine 1976; 55: 39-65.

43 Urban RL, Cotlier E. Corticosteroid-induced cataracts. Surv Ophthalmol 1986; 31: $102-10$

44 Fraunfelder FT, Meyer SM. Ocular toxicity of anti-neoplastic agents. Ophthalmology 1983; 90: 1-3.

45 Deeg HJ, Flourney N, Sullivan KH, et al. Cataracts after total body irradiation and marrow transplantation: a sparing affect of dose fractionation Int $\mathcal{A}$ Radiat Oncol Biol Phys 1984; 10: 957-64.

46 Calissendorff B, Bolme P, Azazi M. The development of cataract in children as a late side effect of bon

47 Green D. The teeth and salivary glands. In: Green D, ed. Long-term complications of therapy for cancer in childhood and adolescence. London: $9: 37-45$

48 Mike V, Meadows AT, D'Angio GJ. Incidence of second malignant neoplasms in children: results of an international study. Lancet 1982; ii: 1326-31.

49 Blatt J, Olshan A, Gula MJ, et al. Second malignancies in very long-term survivors of childhood cancer. Am $\mathcal{F}$ Med 1992; 93: 57-60.

50 Hawkins MM, Draper GJ, Kingston JE. Incidence of second primary tumours among childhood cancer survivors. $B r f$ Cancer 1987; 56: $339-47$.

51 Tucker MA, Meadows AT, Boice JD, et al. Leukaemia after therapy with alkylating agents for childhood cancer. $\mathcal{f}$ Natl Cancer Inst 1987; 78 459-64.

52 Tucker MA, D'Angio GJ, Boice JD, et al. Bone sarcomas linked to radiotherapy and chemotherapy in children. $N$ Engl $\mathcal{F}$ Med 1987; 317: 588-93.

53 Hawkins MM, Kinnier Wilson LM, Stovall MA, et al. Epipodyphyllotoxins, alkylating agents and radiation and risk of secondary leukaemia after alkylating agents and radiation and risk

54 Ron E, Modan MD, Boice JD, et al. Tumours of the brain and nervous system after radiotherapy in childhood. $N$ Engl f Med 1988; 319: 1033-9.

55 Fleming ID, Black TL, Thompson EI, et al. Thyroid dysfunction and neoplasia in children receiving neck irradiation for cancer. Cancer 1985; 55: $1190-4$

56 Deeg HJ, Prentice R, Fritz TE, et al. Increased incidence of malignant tumours in dogs after total body irradiation and marrow transplantation Int $\mathcal{F}$ Radiat Oncol Biol Phys 1983; 9: 1505-11.

57 Witherspoon RP, Fisher LD, Schoch G, et al. Secondary cancers after bone marrow transplantation for leukaemia or aplastic anaemia. $N$ Engl f Med 1989; 321: 784-9.

58 Socié G, Henry-Amar M, Cosset JM, et al. Increased incidence of solid malignant tumours after bone marrow transplant for severe aplastic anaemia. Blood 1991; 78: 277-9.

59 Witherspoon RP, Storb R, Pepe $M$, et al. Cumulative incidence of secondary solid malignant tumours in aplastic anaemia patients given marrow grafts after conditioning with chemotherapy alone [Letter]. Blood marrow grafts after

60 Hughes BR, Cunliffe WJ, Bailey CC. The development of excess numbers of benign melanocytic naevi in children after chemotherapy for malignancy. BMT 1989; 299: 88-91.

61 Hiroyuki T, Morikawa S, Tomika K. Osteosarcoma arising from a multiple exostoses lesion. Case report. fpn $^{\prime} \mathcal{F}$ Clin Oncol 1990; 20: 296-8. 